\title{
A degeneração do bom governo: Entrevista com a Dra. Pilar Ponce Leiva sobre a corrupção na América moderna
}

Thiago Enes ${ }^{1}$

O conceito, a prática e as formas de se combater a corrupção não são em nada distantes da nossa experiência contemporânea, marcadamente a julgarmos pelo atual contexto brasileiro. Contudo, durante muito tempo a corrupção esteve obliterada como um campo de estudo específico da história. Como parte do dossiê "As Américas em tempos de colônia", apresentamos aos leitores da Revista Eletrônica da ANPHLAC uma entrevista com a pesquisadora Pilar Ponce Leiva, professora titular de história da América na Universidad Complutense de Madrid, uma das grandes responsáveis pela viragem historiográfica que vem, mais recentemente, rediscutindo ideias estanques $\mathrm{e}$ preconcebidas sobre um tema tão significativo.

Há muito se dedicando a tópicos correlatos em projetos de pesquisa envolvendo redes internacionais de investigação, entre suas principais publicações destacamos a organização de duas recentes obras ao lado de Francisco Andújar Castilho, da Universidad de Almería. São elas: "Mérito, venalidad y corrupción en España y América - siglos XVII y XVIII”, publicada em 2016, e “Debates sobre la corrupción en el mundo ibérico - siglos XVI-XVIII”, publicada no verão de 2018. Ambas reuniram trabalhos de historiadores de várias instituições da Europa e América com reflexões voltadas sobretudo ao mundo hispano-americano.

Apesar de bastante visitadas, a venalidade e, mais ainda, a corrupção estiveram ancoradas em uma sólida tradição analítica que negava sua existência. Qualquer estudo que se aventurasse a desvendar dinâmicas ímprobas se depararia à frente com uma robusta alegação de anacronismo, assentada no entendimento que via como "natural" e indissociável ao Antigo Regime a lógica de nomeação para cargos administrativos

\footnotetext{
${ }^{1}$ Doutorando em história (UFF) e autor do livro "De como administrar cidades e governar impérios: almotaçaria portuguesa, os mineiros e o poder". PPGH/UFF-Proex/CAPES apoiaram a consecução dessa entrevista, fruto das X Jornadas de Historia Moderna y Contemporánea (Universidad Nacional de Salta/IULCE - Universidad Autónoma de Madrid). Email: enes.thiago@gmail.com [Digite aqui]
}

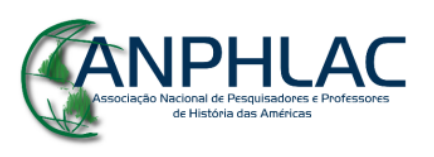


pautada na gramática social do prestígio, e o caráter pessoal e estamental das relações sociais e políticas como um eixo inquestionável e estruturante daquela sociedade. $\mathrm{O}$ patrimonialismo característico da Europa moderna também contribuiu para desencorajar esboços de distinção entre o que era lícito ou ilícito na administração fazendária, no exercício do poder e da política e sobretudo nas relações sociais. No Brasil, o peso da antinomia weberiana entre Estado patrimonial e Estado burocrático serviu de embasamento para grandes interpretações que fundamentaram a corrupção como elemento constituinte e, portanto, naturalizado ao espaço social luso-brasileiro. Não obstante, a intensidade dos méritos, o caráter funcionalista dessa corrupção, as concepções e o exercício de ilicitudes se encontram, atualmente, sob profunda revisão.

Doutora em história e geografia pela Universidad Complutense de Madrid a partir de uma tese que recebeu o "Premio Extraordinario de Tesis Doctoral del Área de América", Pilar Ponce Leiva é especialista em história do Equador na idade moderna, membro correspondente da Academia Nacional de História do Equador, integra grupos de pesquisadores em universidades na Espanha, Portugal, França e Peru, além de ter sido editora-chefe da Revista Complutense de História da América entre 2008 e 2015.

Thiago Enes: En primer lugar, quisiéramos que usted hiciera una presentación de su trayectoria intelectual. En su tesis doctoral usted se ha dedicado a estudiar al Ecuador, más específicamente las elites locales y el Cabildo de Quito. ¿Por qué usted se interesó por la historia de América y como ha llegado al tema de la corrupción?

Pilar Ponce Leiva: Mi dedicación a la historia de la Audiencia de Quito en la Edad Moderna fue el resultado natural de la confluencia de factores profesionales y personales. Estudié historia en la Universidad Autónoma de Madrid y me especialicé en América en la Universidad Complutense; tras unos años en el Consejo Superior de Investigaciones Científicas, realicé el doctorado en la Complutense, siempre teniendo como ámbito de estudio el espacio quiteño. Tal dedicación guarda relación con el hecho de que, aunque lleve cuarenta años viviendo en España, soy ecuatoriana, nacida en Quito, donde aún vive buena parte de mi familia; las constantes visitas a mi país combinaron siempre el [Digite aqui]

$$
\text { CANPHLAC }
$$


encuentro familiar con estancias en archivos y bibliotecas donde consultar la documentación necesaria para mis investigaciones. Por otra parte, la escasez de historiadores dedicados al estudio de la historia de Ecuador - frente a la masiva presencia de colegas volcados hacia Perú y México - me permitió recorrer un camino poco transitado que ofrecía grandes posibilidades de innovación.

La corrupción vino asociada a la venalidad. Como integrante de un proyecto $\mathrm{I}+\mathrm{D}$ sobre venta de oficios en la Audiencia de Quito, participé en varios seminarios en los que debatimos la relación existente entre venalidad y corrupción. Yo mantenía, y aun lo hago, que no fueron prácticas necesariamente asociadas, aunque si tuvieran puntos de contacto en ocasiones. De ahí surgió en 2015 un proyecto coordinado por Francisco Andújar titulado, precisamente, "Entre venalidad y corrupción en la Monarquía Hispánica en el Antiguo Régimen” y, dados los buenos resultados obtenidos, en 2018 nos centramos en otro proyecto esta vez sobre "Dinámicas de corrupción en España y América en los siglos XVII y XVIII: prácticas y mecanismos de control".

TE: ¿Por qué, durante mucho tiempo, la historiografía acusó de anacronismo los enfoques sobre las prácticas corruptas a lo largo de la historia? ¿Qué se entendía como corrupción en el período entre los siglos XVI y XVIII y por qué razón el concepto de corrupción parece poder aplicarse mejor a las sociedades del Antiguo Régimen que a las contemporáneas?

PPL: Detecto tres preguntas en una, así que las responderé por separado:

1.- En una primera aproximación podemos encontrar cuatro argumentos que permiten explicar la consideración de la corrupción como un fenómeno impropio (o anacrónico) en la Edad Moderna.

a) la afirmación de que el término "corrupción" no se utilizaba durante el Antiguo Régimen.

[Digite aqui]

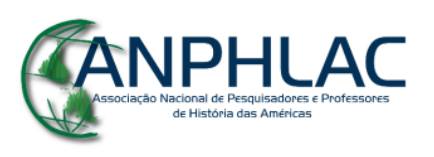

Revista Eletrônica da ANPHLAC, ISSN 1679-1061, № 26, p. 444-451, Jan./Jul., 2019.

http://revista.anphlac.org.br 
b) la afirmación de la inexistencia de una separación entre lo público y lo privado en la administración de la Edad Moderna.

c) la interpretación que del patronazgo y el clientelismo ha dominado los estudios históricos y

d) el carácter funcionalista que se confirió a las prácticas que derivaban en corrupción.

Tales consideraciones han sido debatidas en los últimos años y existe hoy en día un amplio consenso sobre la vigencia en los siglos XVI, XVII y XVIII de un conjunto de prácticas unánimemente percibidas como faltas o transgresiones que remiten a la noción de vicio, estrago, perversión, falsificación, podredumbre, todas ellas expresiones asociadas al término "corrupción", que efectivamente aparece como sustantivo en la documentación de la época, aunque fuera más utilizado el verbo “corromper” y el adjetivo “corrupto", así como "corruptela".

2. En relación a una definición precisa del término "corrupción", el concepto mismo presenta un carácter polisémico, al depender en gran medida de los contextos espacial, temporal y temático (o contexto de uso) en el que se analice. Resulta por tanto imprescindible prestar atención al ámbito en el que se desarrolla el análisis, porque será en función del ámbito escogido que el concepto adquiera unos significados u otros, tanto en las investigaciones actuales como en la percepción del fenómeno por parte de lo coetáneos. Mientras en la esfera política el término se asociaba al nepotismo, al soborno, al abuso de poder - incluso a la tiranía -, desde el punto de vista económico se vincula al fraude, a la estafa, al desfalco; mientras en el campo jurídico el fenómeno se asociaba a la prevaricación, al cohecho, a la concusión o a la entonces llamada baratería, desde el punto de vista moral la corrupción se percibía en la Edad Moderna a través del engaño, la simulación, la ambición desmedida - que desemboca en la avaricia -, la vanidad, la deshonestidad, la deslealtad, la adulación, la ociosidad, la afectación... No cabe duda de que las prácticas sociales que derivan en corrupción hay que considerarlas como parte de una realidad global, que existen en todas las épocas y regiones, pero a la vez resultan

[Digite aqui]

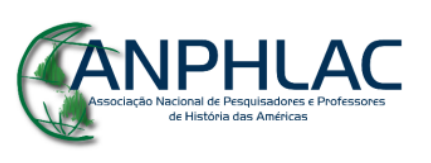

Revista Eletrônica da ANPHLAC, ISSN 1679-1061, № 26, p. 444-451, Jan./Jul., 2019.

http://revista.anphlac.org.br 
incomprensibles si no quedan debidamente insertadas en el contexto en el cual se producen.

En todo caso, puede que nosotros no captemos aun con precisión qué se entendía entonces por corrupción, pero los coetáneos tenían una conciencia razonablemente precisa de su naturaleza delictiva o inmoral.

3. En relación a la tercera parte de la pregunta, el concepto de corrupción como expresión simbólica se asocia a podredumbre física, a degeneración de un cuerpo físico o político. En ese sentido, como ha observado muy sutilmente Adriana Romeiro en su libro Corrupção e poder no Brasil: uma história, séculos XVI a XVIII, "o uso corrente da palavra em nossos dias é uma apropriação anacrônica de um conceito que pouco se adequa a uma sociedade que já não se concebe mais como corpo e, portanto, já não é mais passível de degradação física" (p.33). No creo que haya mejor argumento sobre la adecuación del empleo del término corrupción en la Edad Moderna frente a las acusaciones de "anacronismo" que mencionábamos en la primera parte de la pregunta.

TE: Como sus investigaciones versan tanto sobre América y sobre Europa, ¿es posible afirmar que la corrupción era más intensa en los dominios de ultramar? ¿La distancia del rey perjudicó la conducción del buen gobierno?

PPL: A partir de diferentes estudios fundamentalmente centrados en la figura de los corregidores y los memoriales realizados por los virreyes, se ha generalizado una imagen que presenta la corrupción como un fenómeno notablemente superior en la América Hispana que en la España peninsular. Aun cuando no hay aún estudios comparativos que avalen tal suposición, y a pesar de las evidencias publicadas en los últimos años sobre los altos índices de corrupción existentes en la Península Ibérica a todos los niveles, quizás lo más sensato sea concluir que si en América hubo, efectivamente, más corrupción pudo deberse a la disponibilidad de mayores riquezas y posibilidades de enriquecimiento, y no necesariamente a la debilidad de las instituciones implantadas o a la vitalidad de las prácticas corruptas entre los súbditos americanos, como se ha afirmado.

[Digite aqui]

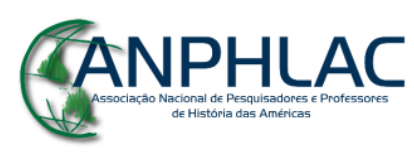

Revista Eletrônica da ANPHLAC, ISSN 1679-1061, № 26, p. 444-451, Jan./Jul., 2019.

http://revista.anphlac.org.br 
Por otra parte, la distancia ha sido considerada habitualmente como un elemento altamente peligroso, que propiciaba tanto distorsiones de la normativa como incumplimientos sistemáticos de ella. En buena lógica esa afirmación debería sostenerse sin dudar, sin embargo, las conclusiones parciales a las que estamos llegando algunos de los participantes en el proyecto "Vencer la Distancia" coordinado por Guillaume Gaudin desde la Universidad de Toulouse sugieren otras posibilidades. Con toda la cautela necesaria, cabe recordar que el "incumplimiento" de las leyes fue -en no pocas ocasionesuna aplicación del jurídicamente regulado principio de "acato pero no cumplo", o del muy eficaz casuismo de la normativa durante los Austrias hispanos; por otro lado, y siempre con la misma cautela, cabe tener presente que la negociación entre rey y súbditos fue considerada desde la teoría política como una necesidad ineludible - y por lo tanto legítima - para la conservación de la Monarquía.

Principios tales como la adaptabilidad, la flexibilidad y la negociación - ejercidos en las dosis convenientes -, permitieron alcanzar el principal objetivo de la Monarquía Hispánica, es decir su propia conservación, sin el cual no se cumplirían ni la expansión de la fe, ni la impartición de justicia, ni el buen gobierno de los reinos que la componían.

TE: En la última edición de la Revista Complutense de Historia de América usted ha organizado un dossier titulado "Debates y consensos en torno a la corrupción en la América hispana y portuguesa, siglos XVI-XVIII”. ¿Es posible hacer un análisis comparativo entre las principales prácticas corruptas de los súbditos de las coronas portuguesa y española? ¿O esas prácticas se asemejaban demasiado?

PPL: Sin duda alguna no sólo es posible sino deseable hacer una comparación entre las principales prácticas corruptas de los súbditos de las coronas portuguesa y española, como lo sería extender el contraste entre los espacios ibéricos y los ingleses, franceses o italianos, por ejemplo. La comparación es siempre un eficaz método de análisis que permite tanto rectificar falsos excepcionalismos como detectar la posición que ocupa cada [Digite aqui]

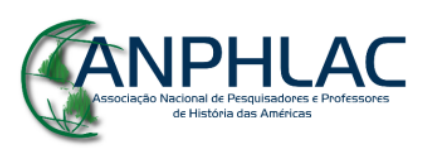

Revista Eletrônica da ANPHLAC, ISSN 1679-1061, № 26, p. 444-451, Jan./Jul., 2019.

http://revista.anphlac.org.br 
elemento en una valoración general. No sólo interesa destacar las diferencias, también las similitudes pueden ser iluminadoras.

En este sentido, en los últimos años se está desarrollando una fructífera colaboración y un enriquecedor diálogo entre las historiografías ibéricas e iberoamericanas que, superando tradicionales compartimentaciones, va poniendo de manifiesto la utilidad de combinar las miradas de amplios horizontes con las perspectivas marcadamente locales y regionales.

TE: En algunos de sus trabajos usted afirma que la corrupción es un campo de estudio consolidado en el americanismo, con una sólida tradición analítica al menos desde la década de 1980, y que llama la atención su escasa implantación tanto en la península ibérica como en el espacio brasileño. ¿Por qué crees que existe esa ausencia de trabajos para Brasil?

PPL: No soy especialista ni en historia ni en historiografía brasileña, de manera que no puedo contestar a esta cuestión con la debida solvencia y precisión. En todo caso, Brasil no sería un caso único en la ausencia de estudios sobre corrupción: tampoco son frecuentes en la historia de la España peninsular. En realidad, los estudios sobre el tema son más bien escasos en todas partes, salvo en la América Hispana.

Llama la atención, sin embargo, que Brasil ofrezca algunos de los textos coetáneos más lúcidos sobre el fenómeno, como esa joya para estudiar la corrupción que es A Arte de Furtar, o los escritos de Antonio Viera. Sea como fuere, como ya han señalado Adriana Romeiro y Maria Fernanda Bicalho el tema de la corrupción si ha estado presente en obras clásicas sobre Brasil (Buarque de Holanda, Caio Prado Júnior, Charles R. Boxer, Raymundo Faoro o Stuart Schwartz), pero no como tópico independiente, sino en relación a la administración y las prácticas de gobierno (sobre todo a las prácticas ilícitas) o, al contrabando (Pijning, Cavalcante, Novais o Kühn). En todo caso, la corrupción tiene

[Digite aqui]

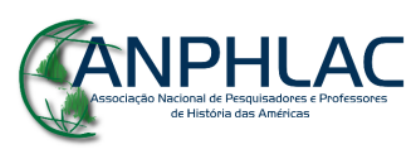

Revista Eletrônica da ANPHLAC, ISSN 1679-1061, № 26, p. 444-451, Jan./Jul., 2019.

http://revista.anphlac.org.br 
actualmente destacados investigadores en Brasil, como son Eik Lars Myrup y, muy especialmente, Adriana Romeiro cuyo trabajo publicado en 2016 resulta modélico.

TE: Para finalizar, hay un planteamiento de que no sería suficiente aludir al tema de los cohechos, sobornos, malversaciones, concusiones y, ante todo, a los excesos desde una perspectiva estrictamente descriptiva, sin embargo porque la temática va más allá de los escándalos que impactaron al público por el monto de los fraudes cometidos o por el daño causado a la comunidad política. ¿Cómo usted cree que los enfoques y las investigaciones deberían caminar en ese sentido?

PPL: Los estudios sobre corrupción suelen centrarse en análisis de casos, dada la importancia del contexto y el tipo de fuentes requeridas. Tales estudios son sin duda necesarios para tener un volumen significativo de datos empíricos, pero no son suficientes. Cada caso debería aportar algunas consideraciones que trasciendan la mera narración de una historia, convirtiéndose en análisis microhistóricos de procesos de larga duración o de amplia operatividad en diferentes contextos. Es interesante, asimismo, analizar la evolución que presentan los discursos sobre la corrupción a partir de fuentes coetáneas, las medidas que fueron diseñándose $\mathrm{y}$, eventualmente, aplicándose para controlar las prácticas que derivaban en la corrupción de los agentes. La implicación de amplios sectores sociales, insertos en diferentes niveles socioeconómicos, es también un campo que puede ofrecer novedosos resultados. En fin, tanto desde la teoría como desde la metodología y los análisis empíricos el tema presenta múltiples vías por las que incursionar.

[Digite aqui]

$$
\text { CANPHLAC }
$$

Revista Eletrônica da ANPHLAC, ISSN 1679-1061, № 26, p. 444-451, Jan./Jul., 2019.

http://revista.anphlac.org.br 